\title{
5 Arenas of Dance among Samburu ${ }^{1}$
}

The general avoidance of dance as a topic for anthropological study reflects the problems of interpreting the art-forms of other cultures, let alone expressing these forms in terms intelligible to our own. Adepts find it difficult but also unnecessary to articulate their feelings or any inner meaning, except through the medium of dance itself. Choreologists have argued that the anthropologists should learn notations for recording body movement as a preparation for fieldwork, yet the aim of such training is to record dance as a museum piece rather than as a performance. It offers no bridge towards an inner understanding that breaks through the cultural barrier on the one hand or resolves the problem of articulating inner feelings on the other. The distance between observer and performer is preserved and dance remains unapproachable for social anthropologists in general, neglected in their training, thereby perpetuating the neglect of this topic and encouraging the field-worker to look elsewhere for significance. Yet dancing is frequently a central spectacle of ritual and other public occasions, and to search elsewhere is to overlook this point, like the proverbial psychologist who turns in his seat at the theatre to peer at the audience. The central preoccupation of the participants is problematic, and the lateral approach, looking elsewhere for significance and understanding, becomes mainstream. This expedient has certainly paid dividends, but there remains the incongruity of Hamlet without the prince.

There is in dance a certain autonomy that can be perceived as an expression of the inner self rather than as a product of interaction with others. This was most explicit in Curt Sachs's monumental World History of Dance (1933), which treats the development of dance as a form of degeneration. In its pristine state, Sachs saw dance as the purest and most private form of religious experience, wholly devoid of society or social context, rather like Colin Turnbull's description of a lone Mbuti pygmy dancing in the forest or a popular view of a child wrapped up in its own play. Other books on the social significance of dance often have an early chapter on its primitive origins - the title deeds as it were - leading up to the present, suggesting a sterile parallel with the early history of anthropology. ${ }^{2}$

Before dismissing this approach as unrewarding conjecture, it is worth pointing to one attempt of this sort that has had great influence on the development of social anthropology: Emile Durkheim's The Elementary Forms of the Religious Life (1915). In

\footnotetext{
1 In its original form, the first part of this chapter has been previously published as 'Dance and the Cosmology of Confidence' in Parkin, D.J., Caplan, L., and Fisher, H. (eds.), 1996, The Politics of Cultural Performance. Berghahn Books, Oxford: (pp. 181-191). The remainder of the chapter was published as 'Dance as Antithesis in the Samburu Discourse', in Spencer, P. (ed.), 1985, Society and the Dance. Cambridge University Press, Cambridge. (pp. 143-64). I am grateful to both publishers for their permission to reproduce these pieces here.
}

2 Sachs 1933, Rust 1969, Lange 1975, Royce 1977

(c))BY-NC-ND (C) 2014 Paul Spencer

This work is licensed under the Creative Commons Attribution-NonCommercial-NoDerivs 3.0 License. 
his search for the essence of religion, Durkheim drew attention to what he regarded as the most primitive form. Dance as such is scarcely mentioned in his account, yet if one considers the most memorable passages of this work, concerning the effervescent euphoria of collective gatherings among Australian aborigines, and then turns to the sources on which he relied, one finds that incessant dancing, singing and processing were constant features. ${ }^{3}$ In other words, dance as a form - even an elementary form - of religious experience has its place implicitly in these passages. In looking beyond the dancing, like so many of his anthropological successors, Durkheim's argument comes close to an interpretation of inner understanding. He did not see the rhythms, stamping and the build-up of dance itself as relevant enough for his argument to elaborate on these; but dancing seems to have been a necessary vehicle for generating the collective sense of occasion that he wished to convey. Durkheim's insight becomes memorable in drawing attention to the collective source of energy and experience vested in the interaction of the group - through the dancing.

The point I wish to pursue is that the success of Durkheim's work was that the thrust of his argument did not rest on evolutionary speculation. He was looking towards relatively undifferentiated societies for an understanding of religion rather than towards some hypothetical ancestor. In doing so, his work provides us with a penetrating model for approaching performance generally, which is embedded in its social context and extends beyond inner feelings to a shared awareness of the powerful forces of collective gatherings. Dance performances may be considered as collective representations in a Durkheimian sense. They express and promote the growth of confidence, a mutual credibility, a gathering will to succeed that is as relevant to appreciating subversive popular movements as it is to understanding the dynamics of normal community existence. Performance impinges on the popular perception of time, space and cosmic forces, and ultimately it reaches towards the fundamental experience of society itself.

\subsection{The Initiation Dance}

In the Maa language, 'play' (enkiguran) is often used as a term for dancing or singing. This is consistent with the apparent triviality of the words of the songs, and the readiness with which a half-muttered song merges into an informal dance movement. On more formal occasions, however, there is a concentration of interest and a sense of power expressed in the compulsive throb of the rhythm generated by the wordless choruses, and body movements characteristic of each dance. It is more than mere play or gossip: it expresses the concerted force of a suppressed sector of their society that has relevance for all.

3 Durkheim 1915: 218; Spencer and Gillen 1904: 375-92. 
This is well illustrated by the role of a particular dance in cultivating an awareness of the development of each age-set cycle among Samburu, which typically spans about 14 years. A new age-set of moran or warriors is established by the initiation of boys in their mid to late teens, and sometimes even in their early twenties. Years before their eventual promotion to moranhood, their dancing is an expression of this desire, as they begin to flex their muscles in anticipation. The moranhood to which they aspire has a unique charm for all Samburu. During the earliest years of childhood, parents may play with their sons on their laps, crooning moran songs, dancing them through the motions of the chorus, and fondly addressing them as 'moran'. As they grow, the education of boys focuses on acquiring basic cattle skills. They may be on cordial terms with their older moran brothers, but outside the family they are despised by moran for their juvenile gaucherie. They are typically 14 years younger than the moran that they will replace, and the moran jealously guard against any attempt by these boys to usurp the privileges of moranhood: their close association with girls, their postures, their songs, their hairstyles and adornments, and the right to shiver in a display of anger.

The unfolding of events leading to new initiations is geared to the rate at which boys mature and at which seasoned moran are prepared to settle down, and this in turn is geared to the rate at which elders are prepared to relinquish their monopoly over marriage by granting them wives. There is no exact synchronisation of this process and no counting the years. The period of transition is one of adjustment to the inevitable in which the boys' performance provides one of the more significant signals.

The first intimations of a new age-set occur when there is restlessness among the older boys. At this stage, there would be no question of openly defying the moran in a premature display of warriorhood and risking a beating. However, a number of boys may muster to dance at night in villages where they are well represented, and the spirit of restlessness spreads. They process around the countryside from village to village after the day's herding, singing and dancing their initiation dance, lebarta. As it is already dark the salient aspect of their performance is in their singing and this can be heard throughout the neighbourhood. The physical assertiveness projected in this vocal display is an aspect of their performance as a group, which also implies dancing: Samburu terms for song and dance are interchangeable. In the boys' experience, lebarta would not have been performed since the last initiations, and the tune and rhythm will be uncertain and variable, only half remembered from an earlier period of their childhood when they were mere onlookers. At first they are unpractised in the idiom and few have voices deep enough to convince the community at large that they are yet fit for moranhood. Displaying themselves hesitatingly at too early a stage merely exposes their immaturity and risks general ridicule. But it is a beginning, and as the boys' voices, confidence, and style develop, so they take heart and use this song and processional dance to recruit other boys to join them. Their numbers swell and they become an increasing presence. During this period, the developing 
timbre of the singing combined with the panache of their dance display is a measure of the mounting strength of feeling and unity among the boys and an indication of the passage of time.

The boys have to demonstrate their credibility as potential moran before they are allowed initiation, and they can only do this by performing their dance and achieving a convincing degree of coordinated self-confidence. The words of the circumcision song hardly change, but there is a hint of mounting tension in its delivery, an irrepressible demand addressed to the elders to recognise that a new set of future moran are proving their mettle. It is the elders who they need to impress in order to hasten their initiation. Ultimately, as the pressure increases, there are incidents of defiance from the oldest boys. With mounting expectations, some leave their homes and herds and wander in pairs or small groups in the bush, impatient and footloose, even pilfering food. Responding to the changing mood, fathers increasingly allow their eligible sons to free themselves from herding, and it then becomes possible to build up a visible and concerted performance during the daytime as they tour the region, processing and dancing, mustering their numbers.

For the moran of the previous age-set, the gathering assertiveness of this dance is a signal of their impending elderhood. Younger moran who were initiated at the tail-end of their age-set may wish to delay any change-over. They therefore assiduously keep the boys in their place and discourage them from any thoughts of an early initiation. Surreptitiously, boys may begin to practise the songs and dances of moranhood and to flirt with the younger girls.

Sooner or later the boys will be able to stand up to their seniors physically and at that point they are fit to take over the coveted role. The older moran do not want to risk the humiliation of having been hounded into elderhood by mere 'boys', and it is in their interests to stand to one side before this point is reached, resigning themselves to a less colourful future as the limelight switches to a new age-set. The elders too realise that they cannot hold onto their monopoly over marriage, denying the moran wives indefinitely. Even less do the elders want to be seen to have aged to the point where they have lost control over the situation as fighting breaks out between ageing moran and overgrown boys. The timing of the change-over with a new spate of initiations is therefore a matter of widespread concern. Many factors are relevant and give clues to the timing, but it is the display of the boys' dancing that is particularly telling. The calibre of this dancing informs popular opinion of the passing of time during this crucial phase of the age-set cycle. In one particular cycle, confidence among the boys may be slow to build up and the period will extend well beyond its normal span. In another cycle, the period may be reduced. Either way, it is the boys' dancing that substitutes for a precise time reckoning. It evokes the growing into manhood of a new age-set with all that this implies for more senior age-sets. Insofar as one can write of the 'meaning' of lebarta among the Samburu, its sight and sound evoke a range of vivid associations extending from a sense of the aesthetic charm of moranhood as a phase of carefree display to a popular awareness of the passage of time. The process 
of ageing, and ultimately the progression of generations are marked by the role of moranhood slipping from one age-set of youths to the next. At a higher level power slips from the age-set of firestick patrons to the next age-set of younger elders, who are increasingly confident of their ability to take over responsibilities for the new age-set.

Even rather young girls play their part in this process. Normally, all unmarried girls share in the general admiration for moran, who may be two or three times their age, joining in their dances and pairing with them as lovers. However, as the boys mature and older girls are married off, so the younger girls begin to hold back. The established moran are now on the brink of marriage and elderhood, and this breaks their charm over these girls, who dread the distant prospect of an arranged marriage to a much older man. The girls are aware of a growing body of maturing youths closer to their own age and poised to take the central arena, and they expect to look towards these for their future companions and lovers. In this way, as the dancing of the boys builds up in confidence, so the dancing of the established moran loses a measure of support from a dwindling number of girls, and this loss of admiration brings their realisation of the inevitability of elderhood another step closer.

Initiation among the Samburu has various symbolic similarities with birth, as though the initiates are 'reborn' in moranhood. Correspondingly, there is a deeply held belief that like unborn and newly born infants, initiates are especially close to God as the ultimate giver of life. As the time of initiation approaches, boys can perform their lebarta further afield with impunity, even beyond the boundaries of Samburu. At such times, it is held that no request should be refused them and anyone who harms an initiate would risk divine retribution. This is shared even by some former enemies of Samburu, such as the Oromo (but not the Turkana, who are seen as relative newcomers to the area). In this way, the time of change-over to a new age-set becomes tinged with a sense of religious awe.

I first became aware of the lebarta dance building up during the spring rains of 1958. This was in an area where the Samburu clans were interspersed, but each village and cluster of villages tended to be associated with just one clan, and the clan above all was the focus of social discourse and identity. Here, it was Pardopa clan in particular that were well represented, and their local network of affiliation became the focus of my study at this stage. The brunt of the daily herding was undertaken by boys, and they would be dispersed with their family cattle for long hours without respite. In the late evening, when the scattered pastoral villages seemed to have settled for the night, spells of dancing with singing could build up among boys or at other times among moran and girls. The moran were not tied down to herding as the boys were, and the locus of moran activity and their dancing tended to shift around the area, reflecting their image as itinerant warriors who were expected to range widely and remain generally vigilant, avoiding involvement in village life and keeping their own company. It was during the late evenings, especially when moran activity seemed quiescent locally, that the boys would dance among themselves. Then as a spirit and cohesiveness built up, they might start singing lebarta, with less emphasis on rhythmic dancing and more on the assertiveness of their singing, voicing their claims to warriorhood, and throwing an implicit challenge to an unseen audience. 
One night, a contingent of perhaps twenty boys from elsewhere processed through the area performing this dance and creating a greater sense of occasion and confidence than I had heard previously, and other boys from the locality joined them. In the days that followed, the moran of Pardopa clan locally discounted the event. They had been involved in their own affairs elsewhere, and the boys would not dare to sport their dances and certainly not lebarta when moran were around, I was told. As matters stood, the initiations of these boys still seemed quite distant. Popular attention was still firmly fixed on the moran, who still had to perform a major ceremony (their 'ilmugit of the bull') before there could be any new initiations, The elders of Pardopa clan, however, were more sensitive to the significance of these boys' dances. They pointed out that the boys were building up a sense of their own strength. The visiting performers had been from other clans, and rather as initiating a new age-set was expected to be a pan-Samburu event, cutting across all clans, so the mustering of the boys was conducted in this spirit, in contrast to the parochial concern for clanship among moran.

Over the next few weeks, I heard lebarta performed on this scale perhaps three more times, breaking the stillness of the night and aware of what appeared to be a gathering momentum. The elders pointed out that the moran would soon perform their ilmugit, and then it would be the boys' turn. It was as if a change-over to a new age-set was imminent. The boys had created a sense of expectation, or at least an awareness that their time would come. However, the apparent momentum behind the boys' lebarta was not sustained during the dry season that followed, and the boys' initiative faded. It was a further four years before the new initiations took place in Pardopa clan, while the existing age-set of moran held their position for a full fourteen years.

Ostensibly, it was a prolonged drought that delayed new initiations, but beyond this, it was the elders who prevaricated. Delay was always to their advantage: both in keeping the moran as just ageing moran, and the boys as just herdboys. In 1958, individual elders locally expressed a willingness to contemplate early initiations, encouraging the boys with assurances (and indeed encouraging the anthropologist to stay longer to see these initiations). However, collectively in delaying any decision, the elders were playing for time and for wives. They had lost their own youthfulness, but it was in their interests to hold high the ideals of youth, encouraging the boys as they also encouraged the moran. The persistence of tradition in Samburu society, in spite of the demise in intertribal warfare, was the persistence of the gerontocratic ideal of polygyny among elders. This ideal brought the vigour of youth, notably through dance, to the centre of the popular stage. It punctuated the sense of time among Samburu, but it also remained geared to the ultimate interests of elders.

Of the various signs that indicate this transitional stage of the age-set cycle, it is the boys' lebarta song and dance in particular that serve as a barometer of the pressures that are building up towards the new set of circumcisions; and the atmosphere becomes filled with an expectation of change-over. This dance is a motif with mixed associations. For the boys' parents, there is pride that their status will be enhanced and the family honour put to the test. For the elders, it anticipates the time when there will be a redistribution of power between the various age-sets that requires careful handling. For the moran, it is an early reminder that their commanding position as 
the centre of popular attention is drawing to an end. A further impressionable group in this process are those boys who are still too young for circumcision even though they may join the periphery of the dancing. A feature that they learn is not just the circumcision song itself (which they may half forget), but also the notion that it is a song and dance of assertiveness against their seniors by age, and that in due course circumcision will only be theirs by uniting to demand it. Through the older boys' lebarta, the seed has been sown for initiations, but also for perpetuating the underlying aspirations of a future, as yet embryonic, age-set of younger boys whose time is not yet ripe.

Between periods of initiation, the moran are suspended in an anomalous role that looks towards the past rather than the present or future, and time in a sense stands still. The boys' lebarta dances are less spectacular than the dances of moran, but in marking the passage of time, there is a potent ring in the way in which they develop into a concerted performance. The period of change-over involves an end to the impasse. There is a general promotion in roles, for boys, for ageing moran, for their parents, and a radical shift in the pressures for marriage affecting girls, and men of all ages. Time is unlocked and social relations are in the throes of change. The passage of time catches up on itself, and with it the passage of ageing. To this extent, the experience of ageing moves fitfully, with the change-over experienced as a radical stride forward. The lebarta dance and the atmosphere it generates conjure up this sense of a special and irreversible event with the initiates at the centre.

\subsection{Wedding Dances}

Samburu elders measure success through their acquisition of wives and steadfastly deny that many of their problems concerning these wives and virile young bachelors stem indirectly from their pursuit of polygyny. It is the dancing at a wedding that brings all these features to a head. A girl is taken away from her moran lover in a marriage arranged by elders for elders. She is circumcised (clitorectomy) and then married in the same ceremony. The wedding is a collective representation of the power of the elders and the impotence of the moran and of the girls and of wives, wrapped up in celebration.

Women's dancing plays a major role in the initial part of the celebrations. Their fertility dances seem very similar to those performed among the Maasai, where the women also sing ribald songs targeting licentious elders in general, and coercing them individually for gifts in exchange for a blessing on their wives.

At a wedding, the women dress up in their finest clothes and adornments. Accompanying their dancing, they taunt the elders in hilarious tones of enjoyment, alluding to their sexual hypocrisies, the impotence of old men, and to outspoken aspects of their own sexual affairs, collectively upturning the subservience of their sex. These songs are mixed with prayers to God for children, with their blessing for the 
fertility of the bride as the central feature. The two aspects of these dances - taunting and praying - are both parts of the same general celebration, and they are held to bring God's blessing to the whole occasion.

By universal acclaim, the principal dances among the Samburu are those of the moran. When the moran appear and start dancing in another part of the wedding village, the women's dancing peters out and attention switches to the moran dancing from that point. Girls too stop their dancing and become the principal spectators of the moran dancing.

With their ostentatious norms of clothing and behaviour, the moran are quite the most colourful feature of Samburu society, and general attention is focused in their direction. Elders recall their earlier period as moran with affection, while regarding the moran with mistrust, amounting at times to a fury over their lapses. Women of all ages dote on the idea of moranhood: as girls with moran lovers, as mothers with moran sons, and as younger wives who should avoid moran but are constantly suspected of adultery. The moran play up to this attention, conscious that their every movement is watched and interpreted by the onlookers.

Compared with the Maasai, the principle of the unity of each age-set is compromised by clan loyalties. Each small village tends to be associated with a clan, linked by clanship to other villages in the same cluster. Elders of a locality convene meetings as autonomous clansmen and arrange clan ceremonies. Moran of a clan form a dispersed peer group over a wider region, and the incipient rivalry between Samburu clans erupts in a form of sporadic gang warfare. This tends to centre on their possession of the girls within each clan as sexual playthings. Any moran can have one mistress from among these girls, and unlike the Maasai, who openly share their lovers, he expects strict fidelity on her part. Because she is a clan 'sister', he may not marry her when he becomes an elder, and he is bound to lose her eventually. But so long as she remains unmarried, his standing among other moran and girls hinges on their relationship. He would be expected to attack any other moran who makes advances towards her or molests her, and if this moran is of some other clan, then feeling may mount and the incident may develop into an inter-clan affray. The significance of their dancing is that dances form the arena in which girls and moran of rival clans may meet in peace. One has, in fact, a situation very similar to the musical drama West Side Story, in which two ethnic gangs of youths keep jealous possession of their girls, but they all meet on 'neutral territory' at dances, where fighting would be a breach of discipline. However, a spontaneous flare-up of hostilities precipitated by some minor incident can never be ruled out.

What constitutes reality for the moran, holding so much glamour and absorbing their energies, is treated by the elders as a mere game among 'children', and they do not readily admit that such affrays are the price that they have to pay for their monopoly of formal power and the destinies of nubile girls. Their ultimate weapon in reining in the moran is their control over the marriages of their daughters, which override the more transient claims of the moran over these girls. It is the elders who 
decide when each bond between lovers should terminate by marrying the girl off to some other clan, where she will start a new life in a position of total subservience.

Thus each wedding is a sharp reminder for all moran and girls of the elders' power to interfere in their affairs, and significantly, the most prominent feature in the ceremony is the dancing of moran, bringing the ultimate impotence of moran to a head, while the elders look on from a discreet distance. Foremost among the spectators are the girls, who are also adorned - even shackled - with multiple coils of bead necklaces and heavy brass coils round their limbs. It is the presence of the girls that makes the moran especially sensitive to any slight or insinuation. They are in an assertive mood with less than total control over themselves, and this adds an undercurrent of apprehensiveness. Their feelings are brittle and no-one can predict exactly how the dance will develop. Events are beyond the immediate control of the elders.

Preparing for a wedding dance, the moran take great care over their appearance, wearing clean cloths wound neatly around their bodies, and a fashionable selection of bead adornments. Glistening red ochre forms a clearly defined pattern around their faces and shoulders, and highlights their long twined hair which hangs loosely behind them. They carry their spears, with the polished, leaf-like blades pointing skywards. Self-consciously they gather at a short distance from the wedding village, snorting in moran fashion, tossing their heads to shake their hair into position, and glancing down at their own appearances. Then as a body they march to the village, watched keenly by everyone, and their dance begins.

This dancing entails a succession of phases, each associated with a characteristic mood. I refer to the first phase, which may last up to one hour or more, as dances of display. In it, one of the more assertive moran takes the role of soloist, boasting in narrative form of his own or his group's prowess and achievements in stock thieving or other exploits (but not their adulteries, for this would alienate the girls who are present). Other moran join in a wordless chorus and occasionally wrest the solo lead. As one worldly moran explained to me: 'It's like an auction, each man tries to bid higher than the last.' Claim and counterclaim build up, while the girls look on. This altercation between 'bulls' (laingok - brave assertive moran) is a dominant feature of the first phase, structuring it up to a point.

Each dance of this phase has its own musical form and pattern of movement. The first dance is invariably nbarinkoi in which the moran form a tight chanting group, and then move forward as a body with a rhythmic movement, twice raising their heels, bending their knees, thrusting their heads forwards and exhaling audibly - in fact not unlike bulls - and then straightening themselves and lifting their spears on the third beat. At certain points individual moran on impulse hop to the front of the dance and beyond. Increasingly others follow suit, and together may leap upwards with rigid bodies. The whole sequence is then repeated several times. Nbarinkoi is the keynote of the whole occasion. If there is a distinct lull during the later stages of the dance or some interruption, the dancers will normally return to nbarinkoi in an attempt to revive it and start anew. This dance appears to be quite invariable throughout the 
Samburu district so that any moran visitor from another clan or region will have no difficulty in participating fully. It sets the tone for the subsequent dancing, displaying the moran as an assertive body of dancers. There is at this stage some competition for the lead, but the soloists' words are generally stereotyped, indistinct and drowned by the chorus.

Another very popular dance of this phase is nkokorri, which gives greater scope for elaboration of the song and competition for the solo part. The loud assertions of the leader are more distinct, and the notion of a multi-sided auction becomes especially apt. A few girls and some rather small boys (too young to be out herding) may join the fringes of this dance, following its movements; but the moran, now facing inwards, take no notice of them. At certain points several moran may spring together in a succession of high jumps.

It is in this dance that one may sense a gathering power and momentum as the rhythm quickens, and sometimes, if guided by a skilful soloist, its rhythm may be elaborated. While it is hard to pin down any precise jealousies aroused by the boasting and counter-boasting, the moran claim that it is at this point that their rivalry and anger come to a head. If a fight breaks out during the dancing, it is likely to be at this stage. Inadvertently one moran may jostle another whose nerves are on edge, and he will react violently. If they happen to be of the same clan and surrounded by their kinsmen, then others may attempt to seize them to prevent a more serious incident. However, if the incident is misconstrued, or there is a score to settle, or they happen to be of different clans, then almost in an instant the dance can be transformed into a general affray.

The possibility of fighting is very real and adds to the tenseness of the occasion, but it is no more than an outside chance. More usually the climax is reached when a number of moran with taut expressions begin to shiver. This is described by the Samburu as a symptom of their anger, a desire to lash out at almost anything, although knowing that they must restrain themselves. In battle, a moran is said sometimes to shiver beforehand until he can release his aggression in the actual fighting, and then he stops shivering. In the dance, his shivering displays his urge to fight and his manliness, but to give way to this urge would show a lack of self-control. It is in this ambiguous and tense situation that one or two moran can be expected to break down in an insensible fit of convulsive shaking, held firmly by their fellows to prevent them from hurting themselves or others. The larger and more successful the dance, the more likely it is that as many as five or more moran will break down in this way, following one another in relatively quick succession. Then after the shaking subsides and they regain their composure, they return to the dance apparently cured of their bout of anger as they merge almost passively into the main body of dancers. The climax of shaking does not necessarily end this display phase of the dance, but it takes away the sense of melodrama, and the moran more obviously enjoy sporting themselves with less compulsion to compete and a greater chance to concentrate on the actual dancing. 
When the dances of display seem to have run their course, moran start to perform dances of the second phase. The girls now join in the dance as a compact group, facing towards the group of moran, and they perform a similar rhythmic thrusting action towards one another. I refer to the dances of this phase as clan dances. The moran and girls of each clan build up a repertoire of songs for those dances (sesiei), generally relating to cattle rustling as in the previous phase, but with a new and more gentle note of competition. They indulge in a game in which the moran tease the girls for their limited knowledge with riddles: 'What is iron that writes?' [Answer - a taipiraita]; 'Who are descended from monkeys?' [Answer - Europeans because they are hairy all over]. The girls respond, taunting the moran for their shortcomings as would-be warriors. It is the skill of individual singers on behalf of their peer group that is now more important than the individualistic assertiveness of 'bulls' noted in the preceding phase.

The tone and topic of this musical repartee is significant. The boundary between the sexes is firm and uncompromising; and there is in addition the vast difference between the worldliness and wanderlust of moran in their twenties and the domestic horizons of girls barely in their teens. In their sparring, based on moranish ideals and sexual attraction, they have little in common outside the idiom of their songs and dances. There is, however, their shared misgiving concerning their subordination to the control of the elders, which expresses itself as a scorn for self-indulgent elderhood tinged with fear of the elders. So long as the moran are footloose and causing trouble through stock thieving they are indirectly provoking the elders, while the girls' encouragement is also an expression of defiance. Just as each wedding is a reminder for the moran of their ultimate powerlessness against the elders who take away their girls, so stock theft has become a symbol of their unwillingness to submit completely. It provides a central topic for the songs of their clan dances. The moran are amused when the girls with their limited experience sing of exploits in a garbled world that they have hardly seen; but there can be little doubt of the effect of the girls' taunting on the moran. Thus a girl may sing: 'If you're a coward who goes out to steal stock and returns with nothing, then you may as well go and dance from village to village [ie. do not return, for the girls will not be impressed]'. Describing the effect of such goading, one moran claimed: 'You are standing there in the dance, and a girl starts to sing. She raises her chin high and you see her throat. And then you want to steal some cattle for yourself. You start to shiver. You leave the dance and stride into the night, afraid of nothing and only conscious of the fact that you are going to steal a cow.' However, one should not underestimate the respect and even fear that the moran have of the elders. Stock theft is a serious problem in the area, but a considerable proportion of moran are thought to go from village to village, goaded by the girls, perhaps even joining in some half-hearted sorties outside the district, but deferring ultimately to the elders. It should also be emphasised that shivering is not common during this phase, and (in my experience) never serious enough to lead to shaking. 
After a while during this phase, a morani may detach himself from his group, go up to one of the girls, and toss his head and flirt his twined hair over her face, or he may just place a hand on her head, and then as the girl shies away from his advances he returns to the body of moran. Other moran follow suit. These sorties gradually become more frequent and dancers on both sides begin to relax. One or two moran may draw some of the girls aside from the dance in conversation. Each sex maintains a certain reserve, remaining as small groups, some silent while others converse by innuendo, adopting the stilted idiom of the singing, teasing, and taunting with well-worn clichés. Yet despite this reserve, one senses a progressive loosening of the atmosphere from the earlier period when the moran ignored the presence of the girls altogether.

This leads to the third phase, which the Samburu term boys' dances. These are not the initiation dance, but a wide selection of dances that the moran performed as boys, and these have remained in their repertoire since they became moran. They are altogether more tuneful than the earlier dances, and the words have a lilt rather than any meaning. The dancing consists of an outer ring of dancers who sing catchy rhythms and beat time, and an inner core who stand in a circle and jump in time. The sexes are mixed to a considerable extent, and small groups beyond the circle of dancers, even pairs, chat and laugh. There is a growing hilarity as the process of thawing out continues. Someone starts to chant to a rhythm that appeals to them all. As one of the dancers once said of this phase: 'When someone beats out the right tune, you find yourself jumping higher and higher and you can't stop.' It is during this phase that moran may make surreptitious advances towards the girls, arranging to meet them at some less public venue, and, if they are not careful, sowing the seed for some future confrontation between rivals.

The transition from one phase to the next appears to depend on the judgement of any skilful singer. At an appropriate point, he may start to sing the first measures of the next phase, and the success of his initiative will depend on the response he gets from others. If they do not share his confidence then the initiative will quickly lapse and the earlier phase will continue. This succession of phases is well illustrated with several examples.

Example 1. Weddings should take place at the time of full-moon; and hence it is common for a number of weddings to take place simultaneously within any region, especially during a wet period. The wedding of Leparit's sister coincided with another wedding nearby that attracted many of the moran from Leparit's clan and left only about ten to attend the wedding dance at his village. They were hopelessly outnumbered by visiting moran, including an impressive contingent from the bridegroom's clan who, with expert singers and dancers, dominated the first phase of the dance and outdisplayed their hosts in front of the girls of the hosts' clan. Leparit and his close friends had been apprehensive of this prospect beforehand, and during the dance itself they were demoralised. At the height of the dance, in quick succession, four of the host 
moran including Leparit broke down and shook, held by their remaining clansmen. The visitors continued to dominate the occasion and none of them shook. Eventually the hosts rejoined the dance, and it proceeded smoothly to the second phase. Although this entailed clan dances, it no longer provoked serious rivalry between the various clans, and the hosts clearly recovered their nerve. The girls only knew the songs of their own (Leparit's) clan, and in singing verses from them they were indirectly lending moral support to their moran kinsmen. For the visitors, the dance had moved on, and any rivalry between versions of this phase became an aspect of the rivalry between the sexes. This second phase was prolonged, and by the time it gave way to the boys' dances of the third phase, many of the visitors had left to return to their own homes, and this became more of a local event and did not last long.

Example 2. Moipa discarded his mistress in disgust after she had been seduced by a moran of another clan. Later, during the display phase of a wedding dance, an affray broke out between the two clans, and Moipa was later accused of having precipitated it by jostling a close clansman of the seducer. The affray was quickly quelled as the local firestick patrons asserted their authority and the dance was abandoned. Subsequently, Moipa's mistress was married off to avoid further trouble, and the elders of the two clans met and agreed to order their respective moran to avoid each other by not attending the same dances until the issue between them had been resolved.

Example 3. At the wedding of Legilan's daughter, several attempts were made by the assembled moran to generate a dance; but for some unexplained reason they lacked the necessary spirit and the dance was unable to develop. Some of the moran started to leave, attracted by the prospect of another dance elsewhere. Those remaining, somewhat dispirited, made a further half-hearted attempt to start the dance, but with even less success. At this point a new contingent of moran, splendidly embellished, arrived and immediately began their own dance in another part of the village. The girl spectators immediately flocked towards this new dance, and the earlier attempt faded out. All the moran now joined the second dance, which proceeded smoothly through each of the phases. Some of the moran shook, but no clear-cut pattern underlay their shaking as had occurred in the first example.

Example 4. At another wedding, a dance had proceeded smoothly through the display dances to the clan dances of the second phase. Then there was a lull, and unaccountably the momentum was lost and the dance stalled. Several attempts to renew this phase found no response among the dancers. The dance then reverted to the display phase, beginning again with nbarinkoi, and on this second occasion proceeded more smoothly through the subsequent phases. (I cannot say whether the initial transition to the phase of clan dances had been premature, but this reversion to the first phase and nbarinkoi following some interruption appears to be the normal pattern.) 
Example 5. (as described by elders). Following the first circumcisions of a new age-set in 1960, two sets of moran dances took place at weddings simultaneously: that of the senior moran due to retire and that of the new age-set of juniors. The junior moran had no established repertoire beyond their boys' dances and they lacked the panache and spectacle of their seniors. Yet time was on their side, and many of the younger girls who had previously been drawn towards the dancing of the senior moran now deserted them and switched their attention to the juniors, whose lack of accomplishment was offset by new hope, high spirits and the remoteness of their own elderhood. With this switching of the limelight away from them, the senior moran began to reconcile themselves to elderhood and lost the incentive to compete or to dance. There was now a radical shift in the type of dancing and singing to be seen at weddings: a fresh unruly spirit mixed in with the various dances that could be expected to lead to a spate of trouble as rivalries built up. But there was also a shift in their language in song. The junior moran sought to establish a new set of songs that they could identify as their own, and up to a point a new slang and double entendre in these songs, a secret language of their own to tease and ultimately share with the girls and to keep hidden from their seniors. Yet despite their efforts to be different, the past experiences of successive age-sets indicated that they would unwittingly continue to follow the basic pattern of dances and of phases as their predecessors.

Example 6. Evening dances begin more spontaneously than wedding dances which always take place during the afternoon, and they are very common. With only moonlight to see by, there are no display dances, and the occasion is marked by informality. In a typical evening dance, a group of moran gather together and call to the girls of the village to come and join them. The idiom of this invitation (ntemerr) is very similar to the clan dances which shortly follow, and thus the dancing may be said to begin with the second phase. This is generally a very local clan affair and the clan dances may last for some time, before the boys' dances of the third phase are attempted. There is in these dances a certain hilarity normally missing from the afternoon sessions. Gradually a fourth phase may emerge, which I would describe as play. The boys' dances begin to lose their form and become mixed with an element of horseplay, which merges into the general babble. Boisterousness increases further and some of the less skilled singers, having lost their earlier inhibitions, may try to take the lead for the first time. The result does little to dampen the high spirits of the dancers. Small groups, or even individuals, begin to jump and dance and beat time, without establishing a rhythm. There is general mirth, and playful skirmishes between moran and girls. Nothing, it seems, can spoil their enjoyment, and the general atmosphere of intoxication may last until the small hours.

As play, this phase is comparable with the attempts of smaller children who earlier in the evening may have mimicked dances that they do not really know, mixing them in with their play. Thus the evening dance starts at a later phase than a wedding 
dance, but progresses in the same direction and, under the discreet cover of darkness, unwinds further.

As the dancing progresses in these examples, one may note a shift of emphasis from the provocative thrusting movement with assertive bull-like grunting that tends to predominate at first, to the leaping movement later on as the rigid bodies of the dancers rise and fall, keeping absolutely together. This is a trend within the first phase and also within the dance as a whole. The horizontal thrusting expresses and even precipitates individualistic competition, whereas the vertical leaping in concert appears to reflect their unity. Increasingly, there is greater emphasis on dances that have more vertical movement, more compulsive rhythms, less grunting, and less competitiveness in their singing.

This development suggests a rather obvious sexual symbolism, even if the Samburu themselves do not emphasise this aspect. 'Bulls' vie assertively in the first phase before an audience of females. They approach these females in the second phase, and the two sexes thrust (their faces) rhythmically towards one another. In the third phase, hand in hand, they spring up and down together as the rhythm grips them, rising to a climax. And then, relaxation. This process may be summarized as

thrusting : competition

$\rightarrow$ springing : unity

$\rightarrow$ unstructured behaviour : relaxed informality.

At a less obvious level, the development of the dance can be taken further. Figure 5.1 depicts the evolution of a moran dance, illustrating this as the reverse of the process of social development of the individual. The dance evolves from the dances of display, in which the moran are disunited and engage in a choral brawl that at any point could degenerate into a fight; the girls are not directly involved at this stage, except as spectators. With the clan dances, the moran are now united and the girls are brought into a game in which brawling gives way to repartee. The two sexes confront each other, at first as peer groups, but progressively as individuals, detaching themselves from the dance, teasing and flirting, while awkwardly maintaining a certain reserve. With the boys' dances, this process of merging is taken a stage further. One is still conscious of small groups of girls clinging together and of moran holding themselves slightly aloof, but the peer grouping of the clan dances is broken up and the verbal play on the periphery rises to a general babble. Finally the last vestige of inhibition appears to evaporate in play and their consciousness of the social barrier that separates them lapses. Perhaps by this stage one should no longer think in terms of the evolution of the dance, but rather of its degeneration.

The process of social development proceeds in the opposite direction. In infancy, the sexes are at first undifferentiated, but with childhood, sharp distinctions are made. Girls should be decently covered and taught to show an early respect for the elders, and boys are involved with a caring concern for stock as soon as possible. 
evolution of a

moran dance

$Y$

CULTURE

phase 1: dances of display

(moran in tense competition)

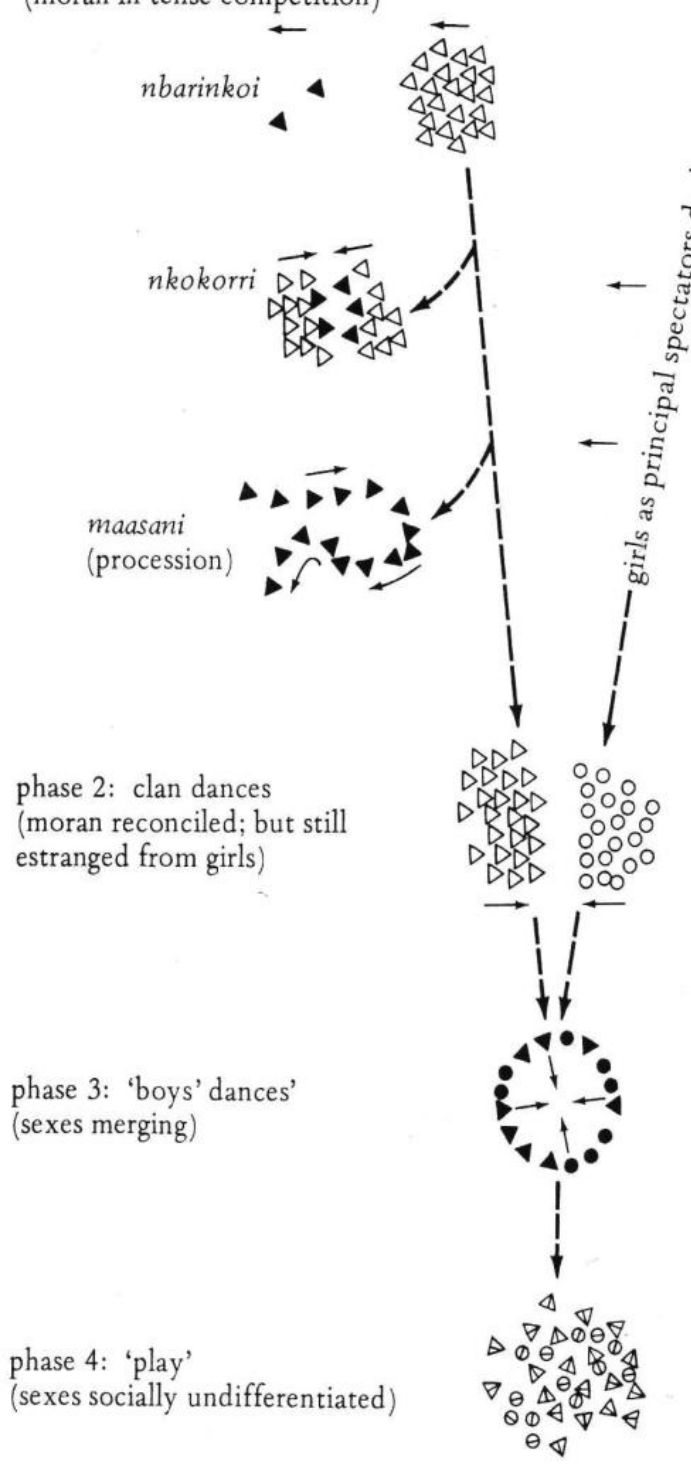

NATURE

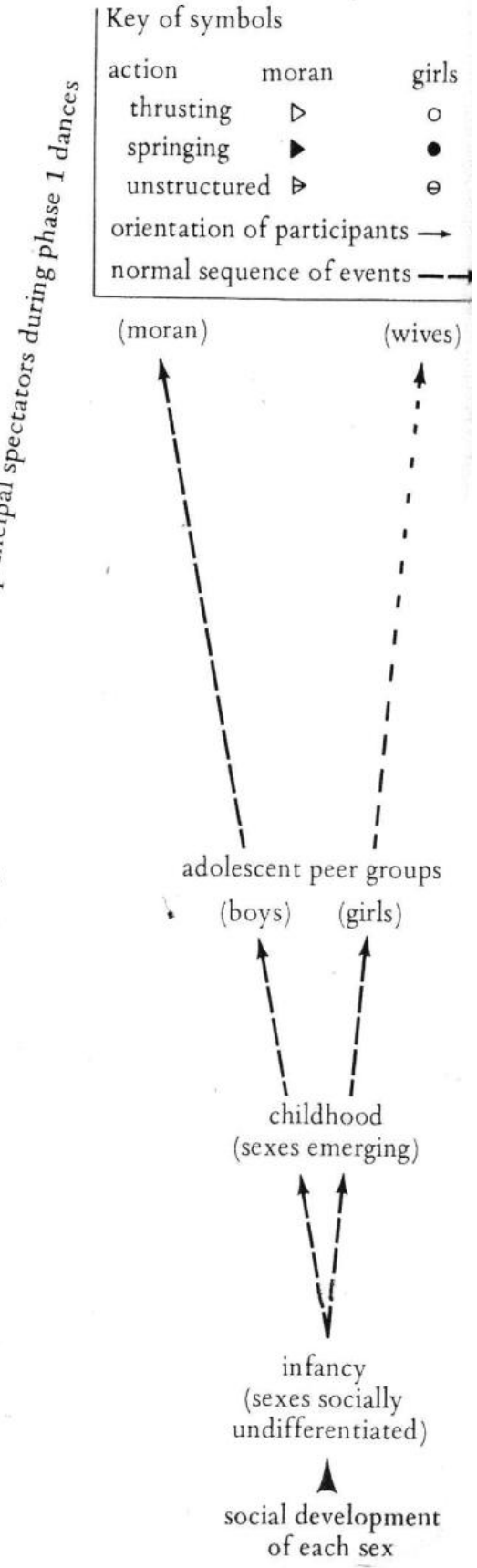

Figure 5.1: Dancing among moran as a process of reversion 
They emerge as separate sexes and long before puberty form themselves into selfconscious peer groups. This process is taken a stage further with their initiation following puberty. At this point the girls are married off individually to elders, and the boys become moran, separated from girls of their own age and frequently at odds among themselves as they are forced to bide their time and are left to create their own subculture over a prolonged period.

This process of social development may be regarded as the progressive imposition of a boundary that separates the sexes and comes between their natural attraction for one another, and then for the men creates further boundaries that divide them among themselves. The moran dance, on the other hand, is a process whereby these boundaries are successively broken down and the shackles of upbringing are progressively shaken off. From this point of view, the dance is not even a degeneration, but rather a retrogression.

Of the various types of explanation that might be put forward for the dances of moran, the evidence here seems to point towards a temporary release of the tension that is built up among young people associated with their restricted position: the moran suspended in a delayed adolescence and young girls with the dismal prospect of an arranged marriage to an elder of another clan. The process might be expressed in Freudian terms as a reversion to infancy; or in Lévi-Straussian terms as a transformation from culture to nature; or following Victor Turner (1969) as a transition from structure to antistructure, with the progression towards play seen as the development of communitas. The moran and girls do not merely release tension, but they also develop a camaraderie, united through the dance in a token protest against the regime under which they are placed. Bringing together these various ways of interpreting the moran dance is revealing. Freud's theory of the development of the personality, conscience, and acculturation focuses especially on the oedipal relationship between children and parents - between inner nature and outer culture. This is a theory that has less to offer on the exposure of the child to other children in spontaneous play, which extends their experience beyond the authoritarian structure of the family and has relevance to the development of relations of equality between peers.

Ostensibly the element of protest in their dances proclaims their autonomy and a challenge to the regime of the elders. Yet in a sense it reintegrates them into society, since it reduces them to the innocuous status of childhood. In this way, a major source of disorder in Samburu society, the threat from dispossessed warriors in their prime, is removed through dance, and order is re-established. Perhaps this is why a lively moran dance at a wedding is regarded as an auspicious event. It exorcises the frustration and anger that builds among younger Samburu and emancipates them. 


\subsection{Dancing and Elderhood}

When the senior moran have settled down as elders, there are no new songs and dances to replace those of their moranhood. The elders are the only sector of Samburu society who do not in practice perform dances (although I was assured that they could and perhaps would), and they can never again wholly recapture the undomesticated charm of their past moranhood. The rift between moran and elders is emphasised, echoing the earlier rift between moran and boys. Reverting to the model of Figure 2.1, one might say that each of the dividing lines in this diagram indicates a social boundary in the distribution of power (by age and by sex), but they also highlight the polarity between complementary opposites. A Samburu definition of an elder would tend to emphasise that an elder does what a moran does not do, and vice versa. If moran dance, shake, and attract popular attention, then it is not appropriate for the elders to attempt these activities. Similarly, because Samburu elders make important decisions in debate, the moran are not encouraged to cultivate debating skills. ${ }^{4}$ The debating elder is as popular a stereotype as the dancing moran.

Yet among elders, their rivalries are played out in debate in a way reminiscent of moran dancing, and one can discern a certain dance-like quality in their deliberations. Joseph Thomson was the first European to traverse the Maa area, and a highlight of his account is his lyrical comments on the visual panache of Maasai oratory, without even understanding their language. ${ }^{5}$ In a Samburu moran dance, a skilful singer can convert an otherwise flat occasion into a memorable one and stimulate others to respond. Similarly, a skilled orator among the elders can convert a meandering discussion into a lively debate. Wielding his stick deftly to make his points (cf. Thomson), he asserts himself as master of the space around him and of the time he takes to hold his audience in his spell. In building up his argument, he provokes other elders to respond and to exercise their skills, wresting the initiative as in an auction. Precisely as a successful moran dance is expected to proceed through the earlier phases of competition before unity is achieved, so the elders should debate, airing all points of view before they arrive at a unanimous decision. An inadequately attended debate, like an inadequately attended dance, does not fulfil its end.

One could argue that this is more than a mere parallel between moranhood and elderhood: it is a transformation from dancing to debating, and an aspect of the transformation from protest to power. On becoming elders, moran enter a new arena, which consciously contrasts with their past in a number of ways. But inevitably there

4 This contrasts with moran among the Maasai, who are encouraged to develop debating skills in managing manyata affairs and this is regarded as a preparation for elderhood. Samburu moran have less encouragement in this respect, delaying their prospects of maturation.

5 Thomson 1885: 162, 433; 1968: 90, 253. 
is a basic continuity, and at a very basic level one might argue that the moran dancers are learning to debate just as the debating elders continue to dance.

\subsection{Conclusion: The Abuse of Power and the Inviolability of Play}

A characteristic feature of Samburu elderhood is drabness of their apparel and their refraining from joining in any dancing, which is the most conspicuous part of Samburu ritual. Admittedly, an element of dance performance has been noted in the skill of oratory when elders are assembled for a debate, but this is most specifically not dance. The Maa term for 'play' (enkiguran) is also used for 'dance', whereas debating is the ultimate tool that elders have in resolving disputes and managing public affairs and in this sense it is the opposite of any form of play. The elders have ultimate authority also within their own households, over their wives, their sons who will eventually inherit from their herds, and their daughters whose arranged marriages will be principally determined by their fathers. The elders are in charge to an ill-defined extent that can border on the abuse of power, especially as perceived by their wives.

Dance as 'play' on the other hand draws attention to dancing as a source of creativity, which stems from a rapport with God as the creator of life itself. In Samburu ritual, dance has a vital role, and where this has a cosmic dimension in popular belief, it endows the arena of dancing with a sense of inviolability. Dancing women are free to enjoy taunting the elders remorselessly. When the moran appear at a wedding dance, parading their finery, asserting their supremacy, outbidding one another in boasting of escapades, they tacitly undermine the authority of the elders. In their dancing as in their expected behaviour generally, the Samburu moran share a sense of unselfish group-indulgence as a virtue of their position. This is compromised when they step up to elderhood and are freed from the selfless constraints of moranhood - and exposed to the inviolable taunts of dancing women.

Dance performance displays a very public message that goes beyond the content of their songs. It expresses the spirit of the occasion. Confidence has to be built up and cannot be taken for granted. Initiates have to reach a standard of coordination and assertiveness before their claim to initiation into moranhood becomes credible. Wives have to muster support from women in neighbouring villages as they gather for a performance at a wedding or for coercing elders of the locality to give them gifts in return for their blessing. The dancing of moran may be let down by under-performance and a failure to establish an empathy or to resolve the tensions between clans. It cannot be assumed that the dancing will always gather momentum or that the stages of a moran dance (Figure 5.1) will always unravel in the prescribed way, as the above examples show. Where moran vie with one another for the lead and start to shake in a fit of anger, or seek to move the dance on to the next phase, there is an element of uncertainty. A dance that peters out is a setback to the panache of the occasion, and 
if this is a wedding, then it casts a shadow over the prospects of the marriage. The loss of spirit in dancing endows less than a full blessing on the occasion. In dancing, nothing succeeds like success, and confidence is built on success.

Just as the elders show little insight into the source of their problems with wives and moran, so they do not suggest that these dances serve to alleviate tensions within the community. However, the elders' explicit stamp of approval and acknowledgement of the central importance of these dances in ritual seem to reflect an intuitive wisdom. They may try to limit the worst excesses of some of the dances (as in the second example above), and realise that the topics of the songs dent the credibility of their regime, but they cannot and do not wish to eliminate the dancing. There is a general notion that these dances are a propitious part of Samburu life. The women's fertility dances are a prayer to God and bring children. Boys' dancing before their initiation has a similar coercive effect, when they are assumed to be protected by God. The spectacle of moran dances is the central feature of display at a wedding and a dismal performance would be regarded as a bad omen, threatening misfortune. These threats, I suggest, are not from malignant outsiders, but express an inner ambivalence concerning the excesses of the rule of the elders. Play is pitted against an over-zealous regime, emancipating the dancers from their shackles. Dancing among the Samburu is a display of the irrepressible antithesis to the shaky premise of gerontocracy. 